Cahiers $d u$ MONDE RUSSE

\section{Cahiers du monde russe}

Russie - Empire russe - Union soviétique et États indépendants

$43 / 4 \mid 2002$

Intellectuels et intelligentsia

\title{
Aleksandr Solženicyn, Dvesti let vmeste (1795-1995)
}

\section{Georges Nivat}

\section{OpenEdition}

\section{Journals}

Édition électronique

URL : https://journals.openedition.org/monderusse/4054

DOI : 10.4000/monderusse.4054

ISSN : $1777-5388$

Éditeur

Éditions de l'EHESS

\section{Édition imprimée}

Date de publication : 30 décembre 2002

Pagination : 784-788

ISBN : 2-7132-1796-2

ISSN : $1252-6576$

Référence électronique

Georges Nivat, «Aleksandr Solženicyn, Dvesti let vmeste (1795-1995) », Cahiers du monde russe [En ligne], 43/4 | 2002, mis en ligne le 18 juin 2009, consulté le 03 septembre 2022. URL : http:// journals.openedition.org/monderusse/4054; DOI : https://doi.org/10.4000/monderusse.4054

Ce document a été généré automatiquement le 3 septembre 2022

Tous droits réservés 


\title{
Aleksandr Solženicyn, Dvesti let vmeste (1795-1995)
}

\author{
Georges Nivat
}

\section{RÉFÉRENCE}

Aleksandr SOLŽENICYN, Dvesti let vmeste (1795-1995). Moscou, Russkij Put', $1^{\text {re }}$ partie, 2001, 508 p. (Issledovanija novejšej russkoj istorii) ${ }^{*}$

1 Un des grands inspirateurs de Solženicyn a été Berdjaev, ou plutôt un certain Berdjaev, celui de la Philosophie de l'inégalité. Les lettres qui composent ce livre sont de pures fictions, mais elles s'adressent à un adversaire (nedrug) qui ne comprend l'homme, la nation, l'histoire que d'une manière abstraite. Un adversaire qui ne comprend ni l'histoire, ni la guerre, ni le corps à corps des hommes et des nations parce qu'il a en tête une idéologie, celle de l'homme abstrait et de ses droits, celle de la nation abstraite et de ses lois, celle du pacifisme et de ses impératifs catégoriques éthiques. Comme Proudhon, comme Spengler, Berdjaev voit dans le corps à corps des hommes simultanément un grand péché et une grande rédemption. Et dans sa " Lettre IV sur la nation », se moquant des internationalistes, il leur lance : «Vous êtes très sensibles à la question juive, vous luttez pour les droits des juifs. Mais sentez-vous "le juif", sentez-vous l'âme du peuple juif, avez-vous pénétré dans tous ses secrets, dans les mystérieuses voies du destin juif qui remontent aux sources antiques de l'humanité ?»

2 Cette apostrophe a tant plu à Solženicyn qu'il la cite au chapitre $x$ de son livre. Il s'agit, à ce moment de la démonstration, de souligner que la deuxième Douma, tout occupée à lutter contre le gouvernement, ne délibéra même pas du projet de Stolypin d'accorder l'égalité des droits aux juifs de l'empire. Solženicyn vient de nous démontrer que Stolypin voulait en finir, mais que Nicolas II refusait de prendre sur lui une telle décision, laquelle lui répugnait. S'appuyant sur les Mémoires du secrétaire d'État Kryžanovskij, et par le jeu d'une citation incomplète, l'auteur de Deux cents ans ensemble pose la question, rhétorique : pourquoi la deuxième Douma (presque mort-née, à vrai 
dire) ne s'est-elle pas emparée du sujet? La réponse est donnée par une autre citation, celle de Berdjaev déjà reproduite : ce n'était pas le juif qui intéressait les maximalistes de la Douma, mais leur lutte avec le pouvoir. La question juive était instrumentalisée, comme toutes les autres, d'ailleurs.

3 L'incroyable puzzle de citations - beaucoup d'auteurs juifs, comme il est souligné - rend la lecture du texte de Solženicyn malaisée parce qu'on peine à distinguer la voix d'auteur. Ce livre est quasiment un "verbatim». Or la poétique de Solženicyn est essentiellement fondée sur l'intrusion de voix d'auteur dans la narration. Son moteur est l'ironie. L'Archipel $d u$ Goulag est une encyclopédie du monde carcéral communiste charpentée par le souvenir personnel (et l'aveu de ses propres faiblesses), et aussi par une énorme ironie à l'adresse de toutes les belles âmes victimes du mensonge idéologique. On retrouve les éléments de cette poétique historienne dans Deux cents ans ensemble, mais contaminés par une troisième composante, dont le rôle a grandi démesurément dans les différents tomes de La roue rouge, le didactisme. À quoi s'ajoute, selon moi, une ambiguïté vis-à-vis du sujet. Car, si Berdjaev récuse les « internationalistes » qui veulent l'égalité de droit pour les juifs sans vraiment « sentir » ce peuple, on peut se demander si Solženicyn « sent » bien le " peuple » dont il a entrepris de dire la vie commune avec les Russes (il ignore tout de la littérature en yiddish). Et on peut également s'interroger sur l'ambiguïté de son rapport aux questions juridiques.

D'une part Solženicyn appartient à une longue lignée de penseurs russes ou assimilés, appelons-les les « slavophiles », pour qui l'essentiel n'est pas le droit comme le voudrait l'Occident, et qui se sont opposés à ceux qui, à chaque étape de l'histoire de la Russie, voudraient que celle-ci s'occidentalisât. C'est ce que disent, chacun à sa façon, Berdjaev et Solženicyn, Leont'ev et Rozanov, ou même Jurij Lotman. Or l'historique que compose Solženicyn porte surtout sur les aspects juridiques et sociaux de la "question juive", très peu sur l'aspect moral, autrement dit on a l'impression qu'il n'applique pas au « problème juif » le même primat éthique que celui qu'il applique au " problème russe ». Et quand Solženicyn cite Vladimir Solov'ev et son projet de manifeste contre l'antisémitisme au lendemain du pogrome de Kishinev (en résumé : ayons un rapport chrétien au peuple juif), on a l'impression que le rapport de l'auteur au grand philosophe, qui convie la Russie orthodoxe précisément à placer le primat éthique et spirituel audessus du juridique, reste légèrement ambigu. Là aussi les guillemets empêchent de deviner si l'auteur adhère ou non à cette position éminemment morale et exclusivement russe de Vladimir Solov'ev. L'allusion au fait que Solov'ev aurait renoncé à publier son manifeste de peur de mesures administratives (de toute façon Solov'ev fut bel et bien mis à pied pour l'appel lancé à Alexandre III afin qu'il grâcie chrétiennement les assassins de son père) nous laisse dans le doute. «Par l'entremise de la police on l'avertit que s'il insistait, il provoquerait une mesure administrative. Il abandonna l'idée.» Comme il s'agit d'un moment crucial du point de vue moral, et du plus éminent philosophe russe, on se demande vraiment dans quelle mesure Solženicyn adhère ou pas au cri de Solov'ev.

Plus généralement on peut se demander s'il ne manque pas une plus ample et généreuse prise en compte de la position prise par Solov'ev, Tolstoj et Korolenko, trois piliers de la conscience russe. " Comme en Europe, la croissance des exigences juives ne pouvait pas ne pas susciter auprès des couches de la société russe - chez les uns l'inquiétude, chez d'autres une opposition brutale, mais chez d'autres encore la sympathie." Solov'ev, Tolstoj et Korolenko sont de ces "autres encore ", mais d'une façon générale cette histoire des rapports russo-juifs comporte très peu de lignes sur l'histoire morale et 
intellectuelle de l'intelligentsia russe (qui, pour ces trois-là en tout cas, avait le courage de ses idées). Un parallèle avec "l'Europe » eût bien sûr été utile; il n'est pas vraiment fait, seulement esquissé par une mention de Drumond. À plusieurs égards par exemple l'affaire Beilis fut, après celle des Protocoles des Sages de Sion ${ }^{2}$, l'équivalent de l'affaire du capitaine Dreyfus: un conflit révélateur entre la vérité factuelle et l'obsession du " mauvais juif ». On sait que Rozanov, aidé par Florenskij, écrivit son livre sur le Rapport olfactif et tactile des juifs envers le sang juste après l'affaire Beilis ; il fut exclu de la « Société de pensée philosophico-religieuse de Saint-Pétersbourg ", mais Aleksandr Blok s'abstint dans ce vote, puis il vint à résipiscence. Solženicyn se veut davantage historien des statuts et des mouvements politiques qu'historien des idées. Principalement, bien sûr, parce que pour lui les "progressistes", l'intelligentsia dans son ensemble ainsi que l'opinion occidentale, ont fait un procès excessif de la Russie, que tout est clair dans le faux domaine des idées, alors que rien ne l'est dans celui des faits avérés. Solženicyn n'est certes pas ici l'avocat du pouvoir (il n'aime pas l'empire qui s'occupe plus de géopolitique européenne que du bien-être russe), mais il est l'avocat d'une Russie trop vilipendée: les pogromes ne furent pas fomentés par les gouverneurs, les chiffres des victimes furent grossis, la directive de Plehve est un faux, etc. Grosso modo, et bien que je ne sois pas spécialiste du tout en cette matière, Solženicyn est convaincant, mais dans un rayon de conviction qui, pour la voix prophétique qu'il représente, me semble étroit, et précisément peu convaincant. Non seulement le lecteur a du mal à vraiment situer l'auteur, comme je l'ai déjà dit, à cause des innombrables citations et de l'ambiguïté des guillemets mais aussi en raison de l'origine soulignée des sources (principalement l'Encyclopédie juive): en histoire, la nationalité ou l'origine de l'historien est-elle si importante, doit-elle être si importante?

Bien sûr le récit qui en résulte est captivant pour qui ignorait le rôle des communautés religieuses, les «kagals », ou encore la mission de Deržavin, ou encore l'épisode des « cantonistes » juifs, la naissance du Bund, etc. Mais ce récit pèche dans la mesure où il fait la part trop belle au juridique et au social, limite le culturel. Et par ailleurs il est placé sous le signe d'un appel à la reconnaissance mutuelle des péchés de l'un et l'autre peuple. Et cet appel, bien intentionné, au mutuel pardon des offenses place d'emblée le récit historien hors des règles ordinaires de l'histoire. On reconnaît le Solženicyn de Sous les décombres mais ici les décombres sont la surabondance des citations, et la voix historienne a autant de mal à percer que la voix prophétique peinait à surgir des décombres soviétiques.

7 Le Solženicyn poète du mot, forgeur de nouveaux et éblouissants substantifs verbaux retenant comme autant de gemmes l'énergie de la dénonciation, de l'ironie ou du regard, est certes encore présent, mais fugitivement. "Longtemps je remettais ce livre à plus tard et j'eusse été heureux de ne point prendre sur moi le faix de l'écrire, mais les délais de ma vie sont à l'épuisé et me faut me colleter.»Cela c'est le Solženicyn d'antan, le petit veau encornant le chêne et, par-ci par-là, quelques néologismes piquants et barbelés nous redonnent l'énergie du vieux maitre, parti à l'assaut d'une nouvelle « zone interdite ». Ici et là apparaissent quelques données personnelles (au collège où étudiait sa mère, à Rostov-sur-le-Don, il y avait plus de la moitié de juives), des soupirs de lutteur incompris (« Pourquoi ai-je dit que l'assassin de Stolypin était un juif? Peu importe que je me sois efforcé d'en faire une description aussi complète que possible. Peu importe ce que le fait d'être un juif a représenté dans les motivations de son acte! Non, la non- 
dissimulation trahissait mon antisémitisme...»). C'est-à-dire que l'on retrouve la poétique du maître. Ou sa trace...

Dans une interview aux Nouvelles de Moscou, Solženicyn a déclaré que ce livre était né dans les marges de la Roue rouge, car il avait rencontré le problème en explorant l'histoire de la Russie antérieure au " nœud » d'Août 14. Il s'agit en somme d'un excursus gigantesque, du genre de celui sur Stolypin ou de celui consacré à Nicolas II (précisément dans Août 14). Un excursus du même genre, didactique, teinté d'humeur et d'ironie personnelle, et destiné à pallier l'ignorance du public sur le sujet. Qui savait, dit-il, que des juifs avaient aidé l'armée russe en 1812 et que la " Volonté du peuple » avait favorisé des pogromes? (Deux exemples pour se «disculper»). La scène célèbre de la « tentation » de Lenin par Parvus, dans un chapitre de Lénine à Zürich, repris dans La Roue rouge, a servi à certains exégètes de "preuve» pour imputer à Solženicyn un antisémitisme de type médiéval. La polémique a évidemment rebondi avec cet ouvrage, et son auteur le savait d'avance. Aux deux bouts du spectre on trouvera d'un côté Leonid Katsis dans Ex libris (12-07-2002) relevant acerbement qu'avec cette compilation "l'Encyclopédie juive devient un organe de la pensée antisémite», et de l'autre côté l'écrivainGeorgij Gačev (Kontinent, $\mathrm{n}^{\circ} 111$ ) voyant dans Deux cents ans ensemble « l'Everest » de l'œuvre de Solženicyn, un modèle de sagesse sine ira et studio. (Mais à vrai dire l'enthousiasme de Gačev est entaché par quelques stéréotypes antisémites, qu'il n'est pas dans mon propos de développer ici).

«Heureux eussé-je été de ne pas éprouver mes forces une fois de plus sur un tel piquant », déclare liminairement l'écrivain. Son ouvrage fait partie de la « masse » ou de l'énorme « décombre » d'une histoire qu'il a empoignée : après le Goulag - la Russie. Et dans ces "décombres" russes, la rencontre avec le peuple juif. Ce n'est donc pas vraiment un livre d'histoire, ce n'est pas non plus le «journal» de sa rencontre avec l'histoire, ce n'est pas tout à fait un prétoire où s'opposent les avocats de deux parties mais l'ouvrage tient un peu des trois genres. Inclassable donc, comme le reste de l'œuvre. Admirable témoin de l'énergie historienne du vieil homme qui voudrait arracher à l'histoire russe le secret de ses « défaillances » successives. Admirable échec néanmoins, car l'historien n'est pas allé aux sources, le publiciste a, dans l'ensemble, négligé l'ample témoignage de la culture russe sur le sujet (car il allait en sens opposé), et le styliste s'est laissé envahir et pervertir par les guillemets. Mais, comme le dit Solženicyn dans Août 14, « l'auteur ne se serait pas permis une rupture aussi grossière de la forme romanesque si la Russie n'avait eu elle-même son histoire rompue, sa mémoire cassée, ses historiens exterminés » (ch. 65).

\section{NOTES}

*. Traduction française : Alexandre Soljénitsyne, Deux cent ans ensemble : 1795-1995, Paris, Fayard, $1^{\text {re }}$ partie, 2002, $572 \mathrm{p}$.

2. Solženicyn les mentionne à peine, or c'est une question qui continue de faire l'objet de recherches et de publications passionnantes, comme celles de Cesare de Michelis ou de Vadim Skuratovskij. 